
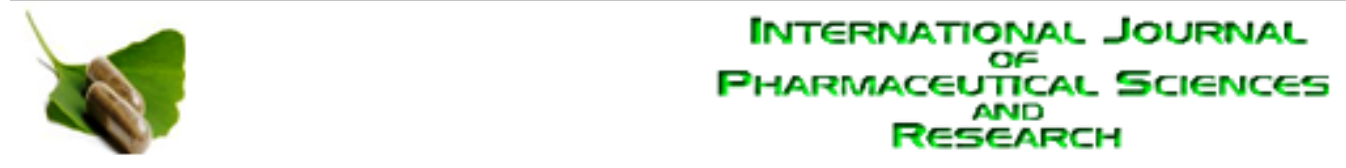

Received on 29 August, 2012; received in revised form 01 November, 2012; accepted 29 November, 2012

\title{
UV-SPECTROPHOTOMETRIC METHOD FOR ESTIMATION OF EFAVIRENZ IN BULK AND TABLET DOSAGE FORM
}

Muni Bhaskar Reddy Chagam Reddy* and G. Venkata Subbareddy Gillella

Rayalaseema University, Kurnool- 518002, Andhra Pradesh, India

Department of Chemistry, JNTU College of Engineering, Pulivendula, Kadapa (Dist) -516390, Andhra Pradesh, India

Keywords:

Efavirenz, Methanol : Double distilled water (30-70), UV-Spectrophotometer

Correspondence to Author:

Muni Bhaskar Reddy Chagam Reddy

Rayalaseema University, Kurnool- 518002, Andhra Pradesh, India

E-mail: cmbr2008@gmail.com

\section{ABSTRACT}

A simple, precise and accurate UV-Spectrophotometric method has been developed and validated for estimation of Efavirenz in bulk and tablet dosage form. It shows maximum absorbance at $320 \mathrm{~nm}$ with methanol and water (30:70). Estimation was carried out by $A(1 \% 1 \mathrm{~cm})$ and by comparison with standard. Calibration graph was found to be linear ( $r 2=0.09657$ ) over concentration range of $1-4 \mu \mathrm{g} / \mathrm{ml}$. The proposed methods appear to be simple, sensitive, and reproducible when checked for parameters like accuracy, precision, limit of detection for routine determination of Efavirenz in bulk as well as in tablet. The methods can be adopted in its routine analysis.
INTRODUCTION: Efavirenz (EFV, brand names Sustiva and Stocrin) is a non-nucleoside reverse transcriptase inhibitor (NNRTI) and is used as part of highly active anti retroviral therapy (HAART) for the treatment of a human immune deficiency virus (HIV) type 1. Efavirenz is chemically described as (S)-6-chloro(cyclopropylethynyl)-1,4-dihydro-4-(trifluoromethyl)$2 \mathrm{H}-3$, 1-benzoxazin-2-one. Its empirical formula is C14H9CIF3NO2. ${ }^{1}$. Efavirenz is a white to slightly pink crystalline powder with a molecular mass of 315.68 $\mathrm{g} / \mathrm{mol}$. It is practically insoluble in water $(<10 \mu \mathrm{g} / \mathrm{mL})^{1}$.

For HIV infection that has not previously been treated, the United States Department of Health and Human Services Panel on Antiretroviral Guidelines currently recommends the use of efavirenz in combination with lamivudine/zidovudine (Combivir) or tenofovir/ emtricitabine (Truvada) as the preferred NNRTI-based regimens in adults and adolescents. Efavirenz is also used in combination with other antiretroviral agents as part of an expanded post exposure prophylaxis regimen to reduce the risk of HIV infection in people exposed to a significant risk (e.g. needle stick injuries, certain types of unprotected sex etc.). ${ }^{1}$. The usual adult dose is $600 \mathrm{mg}$ once a day. It is usually taken on an empty stomach at bedtime to reduce neurological and psychiatric adverse effects. Efavirenz was combined with the popular HIV medication Truvada, which consists of tenofovir and emtricitabine, all of which are reverse transcriptase inhibitors. This combination of three medications approved by the U.S. Food and Drug Administration (FDA) in July 2006 under the brand name Atripla, provides HAART in a single tablet taken once a day. It results in a simplified drug regimen for many patients Efavirenz is used to treat HIV infection. It is never used alone and is always given in combination with other drugs.

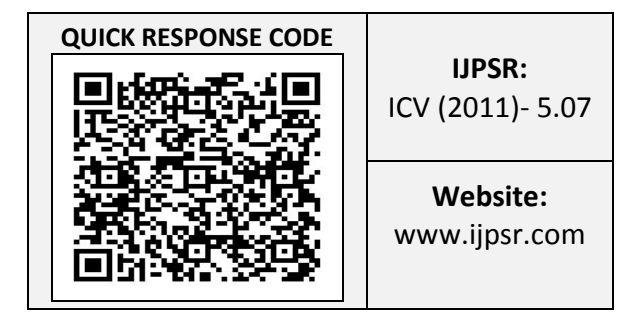


The decision on when to start treatment should take into account CD4 count, HIV viral load, treatment history, resistance profiles and patient preference. Since the preliminary publication of the results of the ACTG 5142 trial in 2006 which compared efavirenz against lopinavir, efavirenz has been used as first line treatment in preference to the protease inhibitors. The ACTG 5095 trial showed that the potency of efavirenz is maintained at all CD4 counts and HIV viral loads. [1] Efavirenz is not effective against HIV-2, as the pocket of the HIV-2 reverse transcriptase has a different structure, which confers intrinsic resistance to the NNRTI class ${ }^{2}$.

As most NNRTIs bind within the same pocket, viral strains which are resistant to efavirenz are usually also resistant to the other NNRTIs, nevirapine and delavirdine. The most common mutation observed after efavirenz treatment is $\mathrm{K} 103 \mathrm{~N}$, which is also observed with other NNRTIs ${ }^{3}$, Psychiatric symptoms, including insomnia, nightmares, confusion, memory loss, and depression, are common ${ }^{4}$ and more serious symptoms such as psychosis may occur in patients with compromised liver or kidney function ${ }^{5,6}$, rash, nausea, dizziness and headache may occur. A general guideline about efavirenz and pregnancy states that efavirenz can cause birth defects and should not be used in women who might become pregnant ${ }^{7}$.

A later study, however, found no increased risk of overall birth defects among women exposed to efavirenz during the first trimester of pregnancy compared with exposure to other antiretroviral drugs 8. Safety in children has not been established Use of efavirenz can produce a false positive result in some urine tests for marijuana ${ }^{9,10}$. Abuse of efavirenz by crushing and smoking the tablets for supposed hallucinogenic and dissociative effects has been reported in South Africa, where it is used in a mixture known as whoonga ${ }^{11,12,13}$.

As with most HIV treatments, efavirenz is quite expensive. A one month supply of $600 \mathrm{mg}$ tablets costs approximately $\$ 550$ in April $2008{ }^{14}$. Some emerging countries have opted to purchase Indian generic ${ }^{15}$ such as Efavir by Cipla Ltd ${ }^{16}$. EFA is a non-nucleoside reverse transcriptase inhibitor (NNRTI) and is used as a part of highly active anti retroviral therapy for the treatment of a human immune deficiency virus ${ }^{17}$.
The drug is used in combination with other anti retroviral agents for the treatment of HIV-1 infection in children and adults. The usual dose of EFA is $600 \mathrm{mg}$ per day (usually give nat bed time).Several methods have been reported for determination of efavirenz. Careri et al., (1993) achieved separation of alkynes by reversed phase HPLC using ruthenium complexes ${ }^{18}$.

Gita et al., (2008) and Agnes et al., (2008) reported separation of efavirenz in human plasma by using reversed phase HPLC technique using C18column. So far in our knowledge only one stability ${ }^{19-20}$ indicating method has been reported using cyano column for the determination of efavirenz (Montgomery ER et al., 2001).

The disadvantage of the method is that its runtime is about 15 min and gradient separation ${ }^{2125}$. The Indian pharmacopoeia (Indian Pharmacopoeia, 2007) Iso published isocratic HPLC method for the assay of EFA. The Run time is about 15 min. $22,24,26$.

The present work describes a simple, economical, accurate and reproducible spectrophotometric method for estimation of efavirenz in pharmaceutical formulations The proposed method was successfully applied for determination of efavirenz in its pharmaceutical formulations.

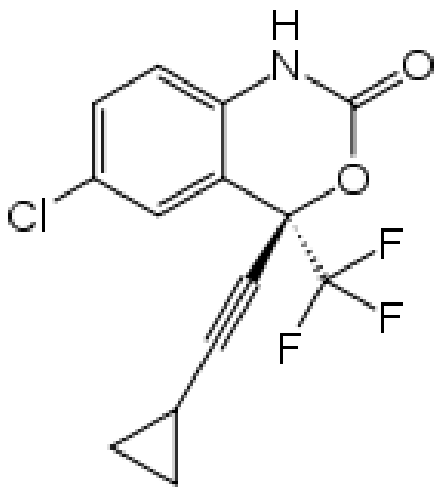

FIG. 1: THE STRUCTURE OF EFAVIRENZ

Systematic (IUPAC) name of Efavirenz is (4S)-6-chloro4-(2-cyclopropylethynyl)-4-(trifluoromethyl)-2,4dihydro-1H-3,1-benzoxazin-2-one.

MATERIALS AND METHODS: The spectrophotometric measurements were carried out using a Schimadzu double beam UV-Visible Spectrophotometer model 1700 with $1 \mathrm{~cm}$ matched quartz cell. 
Reagents: Efavirenz was procured from Matrix Laboratories, Nashik, Maharashtra, India, local pharmacy. Methanol: double distilled water (30:70) used as solvents throughout the experimentation. Pharmaceutical preparation was purchased from local industry.

Standard Solution: The pure drug of Efavirenz about 10 $\mathrm{mg}$ was weighed accurately and dissolved in solvent methanol: water (30:70) to get the concentration of $100 \mu \mathrm{g} / \mathrm{ml}$. Three different methods applied were calibration curve method, single point standardization and two point bracketing method. Solvent system selected was Methanol: Water (30:70). The linearity range was found to be $1 \mu \mathrm{g} / \mathrm{ml}$ to $4 \mu \mathrm{g} / \mathrm{ml}$.

Calibration Curve Method ${ }^{23}$ : In this method, absorbances of a set of standard solutions of reference substance at concentration encompassing the sample concentration are measured and calibration graph is constructed. Calibration curve method is essential for determination of absorbance which has a non-linear relationship with concentration.

Preparation of Calibration Curve: Wavelength of maximum absorption was found to be $320 \mathrm{~nm}$. The absorbance at $320 \mathrm{~nm}$ of eight standard solutions having the concentration range from $1-4 \mu \mathrm{g} / \mathrm{ml}$ was plotted against concentration to get calibration curve.

Analysis of Tablet Formulation ${ }^{23}$ : The Efavirenz tablet solution was prepared in methanol AR grade $(30 \mathrm{ml})$ and was further diluted with double distilled water $(70 \mathrm{ml})$ as described earlier. The concentration of 1.0, $1.5,2.0,2.5,3.0,3.5,4.0 \mu \mathrm{g} / \mathrm{ml}$. Solutions were prepared respectively and the absorbances were measured. The values of absorbance were kept in the calibration curve equation as started above and concentration was evaluated.

Single Point Standardization: The single point standardization procedure involves the measurement of the absorbance of a sample solution and of a standard solution of a reference substance having same concentration. The concentration of substance in the sample is calculated from the proportional relationships that exist between absorbance and concentration.
$C_{\text {test }}=\underline{C}_{\text {test }} \frac{\times C_{\text {std }}}{A_{\text {std }}}$

Where, $\mathbf{C}_{\text {test }}$ and $\mathbf{C}_{\text {std }}$ are the concentration in sample and standard solution respectively. $A_{\text {test }}$ and $A_{\text {std }}$ are the absorbance of the sample and standard solution respectively

Analysis of Tablet Formulation ${ }^{23}$ : Efavirenz Tablet solution was prepared in methanol AR grade $(30 \mathrm{ml})$ and distilled water $(70 \mathrm{ml})$ as described earlier. The concentration of 1.0, 1.5, 2.0, 2.5, 3.0, 3.5, $4.0 \mu \mathrm{g} / \mathrm{ml}$ solutions were prepared respectively and the absorbance were measured. The obtained absorbance value were put in above equation, concentration were calculated.

Double Point Bracketing Method ${ }^{23}$ : Double point bracketing method is required to determine the concentration of sample solution. The concentration of one standard solution is greater than that of sample solution, while other standard solution has lower concentration than sample. The concentration of substance in sample solution is given by equation;

$$
C_{\text {test }}=\underline{\left(A_{t e s t}-A_{s t d 1}\right)} \frac{\left(C_{s t d 1}\right.}{\left(A_{s t d 1}-A_{s t d 2}\right)+A_{s t d 1}}\left(A_{s t d 1}-\underline{A_{s t d 2}}\right)
$$

Where, Std1 refers to standard solution with high concentration. Std2 refers to standard solution with low concentration.

Analysis of Tablet Formulation ${ }^{23}$ : Efavirenz Tablet solution was prepared in methanol AR grade $(30 \mathrm{ml})$ and distilled water $(70 \mathrm{ml})$ as described earlier. The concentration of $1.0,1.5,2.0,2.5,3.0,3.5,4.0 \mu \mathrm{g} / \mathrm{ml}$ solutions were prepared respectively and the absorbance were measured. The obtained absorbance value were put in above equation, concentration were calculated.

Validation of Methods: The proposed methods were validated with respect to linearity, precision and accuracy.

RESULTS AND DISCUSSION: The absorbance was measured at $320 \mathrm{~nm}$ against methanol and the sample solution was computed from calibration curve fig. 1 . 


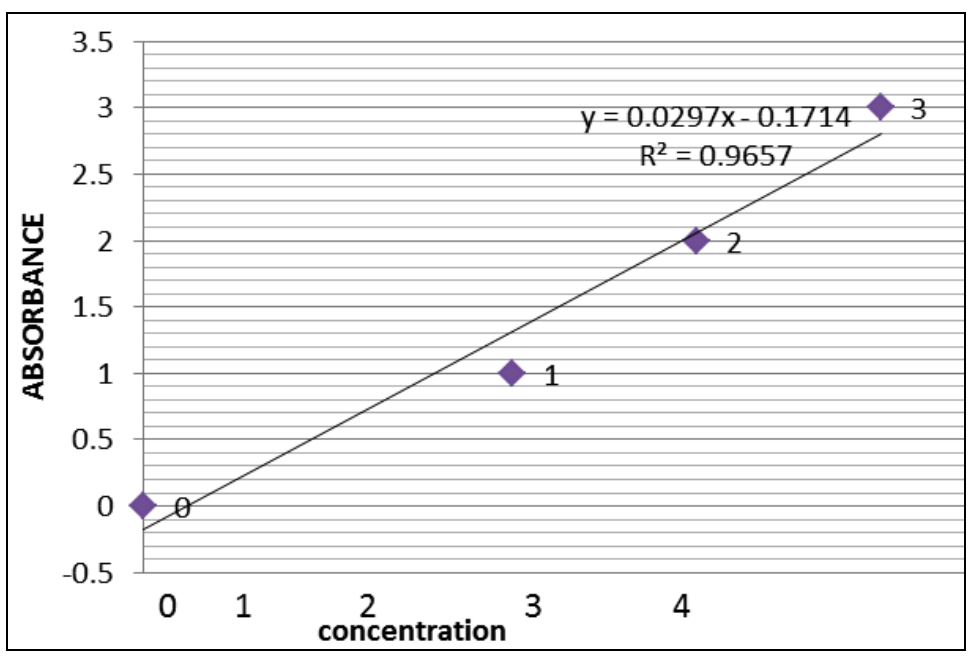

FIG. 2: CALIBRATION CURVE OF EFAVIRENZ

TABLE 1: OPTICAL CHARACTERS OF EFAVIRENZ

\begin{tabular}{cc}
\hline Parameters & Values \\
\hline$\lambda$ max, $\mathrm{nm}$ & 320 \\
Beer's law limit, $\mu \mathrm{g} / \mathrm{mL}$ & $1-4$ \\
Molar absorptivity, $\mathrm{L}$ mol- $1 \mathrm{~cm}-1$ & $1.52 \times 10^{4}$ \\
Regression equation & $\mathrm{y}=\mathrm{a}+\mathrm{bc}$ \\
\hline
\end{tabular}

\begin{tabular}{cc}
\hline Slope $(\mathrm{m})$ & 0.0297 \\
Intercept $(\mathrm{c})$ & 0.01714 \\
Correlation coefficient & 0.9657 \\
\hline
\end{tabular}

The methods were applied for the analysis of the drugs in the tablet formulation. To evaluate the validity and reproducibility of the methods, known amount of pure drug was added to the sample and mean recovery was found to be about $100 \%$.

Validation of Methods: Statistical evaluation is displayed in the table $\mathbf{2}$ and $\mathbf{3 .}$

TABLE 2: STATISTICAL EVALUATION OF EFAVIRENZ

\begin{tabular}{cccc}
\hline Method & $\begin{array}{c}\text { Label claim } \\
\text { (gm/tab }\end{array}$ & $\begin{array}{c}\text { Amount found } \\
\text { (gm/tab) }\end{array}$ & \% found \\
\hline CCM & 1 & 1.007 & 100.7 \\
SPS & 1 & 1.03 & 103.0 \\
DPS & 1 & 1.02 & 102.0 \\
\hline CCM (Calibration Curve & Method), SPS & (Single Point \\
\multicolumn{2}{l}{ Standardization), DPS (Double Point Bracketing Standardization }
\end{tabular}

Standardization), DPS (Double Point Bracketing Standardization

TABLE 3: RECOVERY STUDY DATA OF EFAVIRENZ IN TABLET FORMULATION

\begin{tabular}{|c|c|c|c|c|c|}
\hline Method & Level \% Recovery & \% Recovery Found & Standard Deviation & Coefficient of Variance & R.S.D \\
\hline \multirow{4}{*}{ CCM } & 80 & 111.90 & 0.0352 & 1.83 & 0.0183 \\
\hline & 90 & 113.32 & 0.0346 & 1.71 & 0.0171 \\
\hline & 100 & 111.97 & 0.0522 & 2.45 & 0.0245 \\
\hline & 120 & 109.91 & 0.0707 & 3.04 & 0.0304 \\
\hline \multirow{4}{*}{ SPS } & 80 & 115.25 & 0.352 & 1.83 & 0.0183 \\
\hline & 90 & 113.88 & 0.036 & 1.75 & 0.0175 \\
\hline & 100 & 113.7 & 0.053 & 2.4 & 0.0240 \\
\hline & 120 & 110.41 & 0.070 & 3.04 & 0.0304 \\
\hline \multirow{4}{*}{ DPS } & 80 & 112.5 & 0.0311 & 1.61 & 0.0161 \\
\hline & 90 & 113.33 & 0.0335 & 1.74 & 0.174 \\
\hline & 100 & 116.0 & 0.0494 & 2.31 & 0.0231 \\
\hline & 120 & 110.0 & 0.0789 & 3.05 & 0.0305 \\
\hline
\end{tabular}

CONCLUSION: Thus, it can be concluded that the methods in present investigation were simple, sensitive and reproducible when checked for parameters like accuracy, precision and limit of detection for routine determination of Efavirenz in bulk as well as in tablet.

ACKNOWLEDGEMENT: Authors are thankful to the Principal, HOD of Chemistry, Dr. G.V. Subba Reddy Jntu College of Engineering \& Technology, Pulivendula, Kadapa (Dt) Andhra Pradesh, India, for providing research facilities for this work.

\section{REFERENCES:}

1. http://en.wikipedia.org/wiki/Efavirenz
2. Ren J, Bird LE, Chamberlain PP, et al. (2002). "Structure of HIV-2 reverse transcriptase at 2.35-A resolution and the mechanism of resistance to non-nucleoside inhibitors". Proc Natl Acad Sci USA 99 (22): 14410-15. doi:10.1073/pnas.222366699. PMC 137897. PMID 12386343.

3. Sustiva (efavirenz) capsules and tablets. Product information (April 2005)

4. Cespedes, MS; Aberg, JA (2006). "Neuropsychiatric complications of antiretroviral therapy.". Drug safety : an international journal of medical toxicology and drug experience 29 (10): 865-74. doi:10.2165/00002018-200629100-00004. PMID 16970510.

5. Hasse, B; Günthard, HF; Bleiber, G; Krause, M (2005). "Efavirenz intoxication due to slow hepatic metabolism". Clinical Infectious Diseases 40 (3): e22-3. doi:10.1086/427031.PMID 15668854.

6. Lowenhaupt, EA; Matson, K; Qureishi, B; Saitoh, A; Pugatch, D (2007). "Psychosis in a 12-year-old HIV-positive girl with an increased serum concentration of efavirenz". Clinical Infectious Diseases45 (10): e128-30. doi:10.1086/522764. PMID 17968817. 
7. DHHS panel. Guidelines for the use of antiretroviral agents in HIV-1-infected adults and adolescents (October 10, 2006). (Available for download from AIDSInfo)

8. Ford, N.; Mofenson, L.; Kranzer, K.; Medu, L.; Frigati, L.; Mills, E. J.; Calmy, A. (2010). "Safety of efavirenz in first-trimester of pregnancy: A systematic review and meta-analysis of outcomes from observational cohorts". AIDS 24 (10): 1461-1470. doi:10.1097/QAD.0b013e32833a2a14. PMID 20479637. edit

9. Rossi, S; Yaksh, T; Bentley, H; Van Den Brande, G; Grant, I; Ellis, $R$ (2006). "Characterization of interference with 6 commercial delta9-tetrahydrocannabinol immunoassays by efavirenz (glucuronide) in urine". Clinical chemistry 52 (5): 896-7. doi:10.1373/clinchem.2006.067058. PMID 16638958.

10. Röder, CS; Heinrich, T; Gehrig, AK; Mikus, G (2007). "Misleading results of screening for illicit drugs during efavirenz treatment". AIDS (London, England) $21 \quad$ (10): 1390-1. doi:10.1097/QAD.0b013e32814e6b3e. PMID 17545727.

11. IOL: Thugs get high on stolen AIDS drugs

12. Getting high on HIV drugs in S Africa. BBC News, 8 December 2008.

13. 'No Turning Back': Teens Abuse HIV Drugs. ABC News, April 6, 2009.

14. Price listed on http://drugstore.com website, $4 / 20 / 2008$

15. IndiaDaily - A new trend in emerging nations - Brazil opts for Indian generic drug ignoring US pharmaceutical giant Merck's patent on AIDS drug Efavirenz

16. www.cipla.com
17. Sütterlin, S., Vögele, C., \& Gauggel, S. (2010). Neuropsychiatric complications of Efavirenz therapy: suggestions for a new research paradigm. The Journal of Neuropsychiatry and Clinical Neurosciences, 22(4), 361-369.

18. Agnes IV (2008). Separation of efavirenz in human plasma by using reversed phase HPLC technique J. Chromatogr. B. 734(1): 55-61.

19. Careri M (1993). Particle beam liquid chromatography-mass spectrometry behavior of polynuclear metal carbonyl compounds, J.Chromatogr. 647: 79-90.

20. Gita R (2008). Simple and rapid liquid chromatography method fordetermination of efavirenz in plasma. J. Chromatogr. B. 835: 131-650 Afr. J. Pharm. Pharmacol.135.

21. . Indian Pharmacopoeia (2007). Volt. 2. The Indian Pharmacopoeiacommission, Ghaziabad -India pp. 1071-1074.

22. Montgomery ER (2001).Development and validation of a reverse phaseHPLC method for analysis of efavirenz and its related substances indrug substance and capsule formulation. J. Pharm. Biomed. Anal. 2 5:267-284.

23. A.H. Beckett, J.B. Stenlake: Practical pharmaceutical chemistry, part 2, 2004; CBS publication: 279-281.

24. Martindale: the complete Drug Reference 34th edition published by pharmaceutical press: 615.5 .

25. The Merck Index: An Encyclopedia of Chemicals Drug, and Biological, 13th edition, published by Merck \& company: 8494

26. Holler, skoog. Crouch: Principles of instrumental analysis; 6th edition, Thomson publication, 337.

How to cite this article:

Reddy MBRC and Gillella GVS: UV-Spectrophotometric Method for Estimation of Efavirenz in Bulk and Tablet Dosage Form. Int J Pharm Sci Res. 3(12); 5033-5037. 